\title{
Horizontal analysis and vertical comparison of science and technology input in Guangdong province
}

\author{
Xing Shaojing ${ }^{1, a}$,Bai Defa ${ }^{2, b}$ \\ ${ }^{1}$ Science and Technology Department of Jinan University, Guangzhou 510632, Guangdong, Peoples R \\ China \\ ${ }^{2}$ Science and Technology Department of Jinan University, Guangzhou 510632, Guangdong, Peoples R \\ China \\ aemail:txingsj@jnu.edu.cn, bemail: 83657046@qq.com
}

Keywords: Guangdong province, science and technology input, R\&D

\begin{abstract}
Further adjusting the structure of science and technology input is needed for creating an Innovative Guangdong. The paper analyses the financial input of $R \& D$, capital and investment structure from the vertical and horizontal two aspects over the past decade. By comparing with other provinces at similar levels of economic development and the Asian tigers, it aims to find out the problems of input and give suggestions.
\end{abstract}

\section{Introduction}

Technological innovation is the key to economic growth, and the important driving force to improve the market competitiveness. Science and technology is primary productive forces, is the support force to promote comprehensive, coordinated and sustainable economic and social development. To make the technology become a strong economic development support, countries or regions must increase investment in science. As a pioneer of China's reform and opening up, Guangdong Province has made remarkable achievements in the industrialization, urbanization, and the foreign economic development. The growth rate of annual GDP over $10 \%$ for many years, Guangdong province has become one of the greatest contributions to national GDP. All of these, not only benefited from the excellent location but also the investment in science and technology ${ }^{[1]}$. How about the situation of the investment in science and technology of Guangdong Province? Are there also deficiencies? what is the disadvantage after the comparison of financial technology investment between Guangdong and other Provinces as well as Four Asia tigers?

\section{Comparisons}

2.1 The comparison between Guangdong and other Provinces. As the forefront and integration testing ground of China's reform and opening up, Guangdong province has effectively promoted the process of modern civilization and the China's reform and opening up. To keep rapid economic development, we must increase investment in science and technology. The scale and intensity of R\&D as international common indicator reflect scientific and technological strength and core competitiveness of a regional. The comparison of financial technology investment between Guangdong and other provinces can reflect the level of Guangdong province’s technological investment.

In 2010, Guangdong's R\&D funds ranked third in the country, in absolute terms, Guangdong's $\mathrm{R} \& \mathrm{D}$ funds was 80.87 billion yuan, there's little distance compared to the first place of 85.79 billion yuan in Jiangsu province. But, from the rate of R \& D funds in GDP (table 1). There's serious shortage of the R\&D funds. In 2010, Guangdong's GDP totaled 4.547283 trillion yuan, is the highest province with the total GDP, per capita GDP was 43,600 yuan, annual growth rate is $12.2 \%$. However, the

Project supported by ”the Fundamental Research Funds for the Central Universities” 
proportion of science and technology funds in GDP accounted for was only $1.76 \%$, the second-lowest in six provinces, in terms of apparent low as opposed to $5.82 \%$ in Beijing and $2.81 \%$ in Shanghai, indicating that the investment in Guangdong Province is seriously inadequate.

Table 1 the proportion of R\&D funds in GDP or government money in 2010 [billion yuan]

\begin{tabular}{cccccc}
\hline Provinces & R\&D & GDP & $\begin{array}{c}\text { Governme } \\
\text { nt funds }\end{array}$ & $\begin{array}{c}\text { R\&D / } \\
\text { GDP }\end{array}$ & $\begin{array}{c}\text { R\&D / } \\
\text { Government funds }\end{array}$ \\
\hline Beijing & 82.18 & 1377.794 & 47.21 & $5.82 \%$ & $57.45 \%$ \\
\hline Shanghai & 48.17 & 1687.242 & 14.28 & $2.81 \%$ & $29.65 \%$ \\
\hline Jiangsu & 85.79 & 4090.334 & 11.45 & $2.07 \%$ & $13.35 \%$ \\
\hline Zhejiang & 49.42 & 2722.675 & 4.799 & $1.78 \%$ & $9.71 \%$ \\
\hline Shandong & 67.2 & 3941.620 & 5.888 & $1.72 \%$ & $8.76 \%$ \\
\hline Guangdong & 80.87 & 4547.283 & 6.576 & $1.76 \%$ & $8.13 \%$ \\
\hline \multicolumn{6}{c}{ Sources data from China statistical yearbook on science and technology $2011^{12}$}
\end{tabular}

2.2 The comparison between Guangdong and Four Asia tigers. With the reform and opening up, Guangdong province has undergone enormous changes. In proportion to the size of economy, Guangdong has been catching up Singapore, Hong Kong and Taiwan, is expected to surpass South Korea in 2015, and become the first veritable economic province of mainland china ${ }^{[4]}$.Now, there will to compare the rate of R \& D funds in GDP between Guangdong province and "Four Asian Tigers".

Table 2 the proportion of R\&D funds in GDP from 2001 to 2010 [\%]

\begin{tabular}{ccccc}
\hline Year & South Korea & Taiwan & Singapore & Guangdong \\
\hline 2001 & 2.59 & 2.08 & 2.11 & 1.27 \\
\hline 2002 & 2.53 & 2.18 & 2.15 & 1.33 \\
\hline 2003 & 2.63 & 2.31 & 2.11 & 1.34 \\
\hline 2004 & 2.85 & 2.38 & 2.20 & 1.14 \\
\hline 2005 & 2.98 & 2.45 & 2.30 & 1.12 \\
\hline 2006 & 3.01 & 2.51 & 2.16 & 1.19 \\
\hline 2007 & 3.21 & 2.57 & 2.37 & 1.30 \\
\hline 2008 & 3.36 & 2.78 & 2.65 & 1.41 \\
\hline 2009 & 3.56 & 2.94 & 2.24 & 1.65 \\
\hline 2010 & 3.74 & 2.90 & 2.09 & 1.76 \\
\hline
\end{tabular}

Sources data from China statistical yearbook on science and technology $2012^{[2]}$ and Guangdong Province statistical yearbook on science and technology, 2002-2011 ${ }^{[3]}$

Although Guangdong's GDP has surpassed Singapore, Hong Kong and Taiwan, but the rate of R\&D expenditure in GDP is far below these regions. Guangdong Province in 2010 the proportion of R\&D expenditure in GDP of Guangdong Province has rose to 1.76\% in 2010, but the proportion of R\&D expenditure in GDP of South Korea in 2010 has reached 3.74\%, more than twice that. The proportion of R\&D expenditure in GDP of Taiwan and Singapore were also reached $2.90 \%$ and $2.09 \%$ respectively, much higher than Guangdong province, which show that financial investment of Guangdong Province in science and technology are insufficient.

\section{The investment of Guangdong Province in science and technology over the years}

After the horizontal comparison between Guangdong and other provinces of china, and some countries, then there's a longitudinal comparison, to analysis of some problems about Guangdong fiscal investment in science and technology.

3.1 Technology and GDP development is uncoordinated. The economic achievements of Guangdong are absolutely huge in the past thirty years of reform and opening-up. However, the 
development of science and technology has failed to keep up with the pace of growth in the GDP. There's an analysis of relative data.

Guangdong is the province with the highest total GDP, and maintain long-term annual GDP growth of about $8 \%$, its economic strength is very strong, but its scientific and technological developments has gone sideways. The data from table 3 show that, both $\mathrm{R} \& \mathrm{D}$ expenditure and science and technology funds are low share of GDP, and no significant rise in the proportion over the years.

Table 3 the share of Guangdong's science and technology funds in GDP or government funds for science and technology from 2001 to 2010[billion yuan]

\begin{tabular}{ccccccc}
\hline year & $\begin{array}{c}\text { S\&T } \\
\text { funds }\end{array}$ & $\begin{array}{c}\text { S\&T/G } \\
\text { DP [\%] }\end{array}$ & R\&D & $\begin{array}{c}\text { R\&D/GDP } \\
\text { [\%] }\end{array}$ & $\begin{array}{c}\text { Government } \\
\text {-funded for } \\
\text { S\&T }\end{array}$ & $\begin{array}{c}\text { S\&T / fiscal } \\
\text { spending } \\
\text { [\%] }\end{array}$ \\
\hline 2001 & 25.043 & 2.37 & 13.42 & 1.27 & 4.077 & 3.09 \\
\hline 2002 & 29.13 & 2.47 & 15.645 & 1.33 & 5.77 & 3.79 \\
\hline 2003 & 33.24 & 2.44 & 17.984 & 1.34 & 5.656 & 3.34 \\
\hline 2004 & 38.924 & 2.11 & 21.519 & 1.14 & 6.54 & 3.53 \\
\hline 2005 & 45.636 & 2.04 & 24.96 & 1.12 & 8.377 & 3.67 \\
\hline 2006 & 54.191 & 2.2 & 31.304 & 1.19 & 10.41 & 4.08 \\
\hline 2007 & 68.685 & 2.21 & 40.55 & 1.30 & 11.926 & 3.78 \\
\hline 2008 & 84.465 & 2.36 & 50.457 & 1.41 & 13.252 & 3.51 \\
\hline 2009 & - & - & 65.298 & 1.65 & 16.85 & 3.89 \\
\hline 2010 & & & 80.875 & 1.76 & 21.444 & 3.96 \\
\hline
\end{tabular}

Sources data from Guangdong province statistical yearbook on science and technology, 2002-2011 ${ }^{[3]}$

3.2 Investment in basic research is not enough. By OECD (Organization for Economic Cooperation and Development), R\&D activities are divided into three categories: basic research, applied research and experimental development. As the foundations of science of the country, basic research is a source of innovation. The share of basic research in R\&D expenditure reflects the structural condition and the knowledge creation and innovation activities of the original proportion.

The data of R\&D in 2001-2010 show that, the proportion of expenditures for basic research of Guangdong province is basically below 2\%, and it's 1.49\% in 2007, even lower than that of 2003-2006. Government spending on applied research is among 4\%-5\% of GDP, and it's more than 90\% that spending on experimentation and development funds. The proportion of funds for basic research is extremely unreasonable. Not only there is a gap between the proportion of Guangdong and the national average (about 5\%), but also a wide gap between Guangdong and other countries, for example, USA (15\%-20\%, 17.4\% in 2008), Japan (12\%-15\%, 8.8\% in 2008), South Korea (about 15\%, 16.1\% in 2008), Russia (21\% in 2009). Although the proportion of basic research has increased from 2008 but with very low ratios, and significant problems remain.

3.2 The funds in R\&D for Research institutions and universities is low share. The development and progress of society need to have enough, high technology content of scientific and technological achievements. Research institutions and universities are the powerful motive force for the sustainable development of science and technology, and the main force of basic research. The total R\&D of Guangdong Province is 50.457 billion yuan in 2008, the proportion of research institutions, universities and enterprises is $2.42 \%, 4.27 \%$ and $92.92 \%$ respectively. In 2009 , the total R\&D is 65.298 billion yuan, the proportion of Scientific research institutions, universities and enterprises is $2.7 \%$ 、 $3.7 \%$ and $92.0 \%$. All of these obvious showed that the investment for research institutions and universities is too low, so that there are no great scientific research achievements. 


\section{Conclusions and Recommendations}

In a word, there are some of the key problems that reflect financial investment in science and technology, for example, technology and GDP development is uncoordinated, shortage of investment funds, low proportion of investment in basic research, The role of research institutions and universities failed to emerged. Aiming at these problems, two advices are put forward.

4.1 Increase the financial technology funding for R\&D funds, especially the investment in basic research. $R \& D$ investment intensity of innovation-oriented country is closely related to the economic strength and the level of economic development. Roughly as follows, while GDP per capita of a developing country is below $\$ 1000$, the level is still in the stage of technology introduction and imitation, the ratio of R\&D in total GDP is less than $1 \%$. But while in the above $\$ 1000$, the R\&D funds accounted for the proportion of GDP is often more than 1\%, and the technology enter to the stage of digestion, absorption, improvement(e.g. japan in the 1960s). In the stage of technological innovation, the proportion is often more than $2 \%$. At present, R\&D funds accounted for the proportion of GDP is $1.4 \%$ in Guangdong province, and it's still far from the stage of technological innovation. To enhance the capability of independent innovation, the government of Guangdong must strongly increase investment funds for science and technology to provide better conditions and platform for experts, scholars, science and technology talents and all kinds of science and technology person. So, the government of Guangdong province should further strengthen the $\mathrm{R} \& \mathrm{D}$ funds to combine the investment in science and technology with economic strength more effectively.

The proportion of the R\&D funds in GDP is generally higher than $4 \%$ in developed and newly industrialized countries, while the data of developing countries is generally lower than $2 \%$. But generally speaking, there are characteristics of high risk, long cycle and uncertain return for basic research. So, financial investment, who contributes significantly to increase the basic research, must take on the role of principal ${ }^{[5]}$. In addition to increase $R \& D$ funding, the government also need a reasonable scaling to guide and increases the proportion of funding for basic research ${ }^{[6]}$.

4.2 Increase financial funds in science and technology research to institutes and universities. There's not enough funds to support institutes and universities, especially the total number of Universities in Guangdong Province are more, but a small number of research universities of national top 20, low proportion of university research contribution, so that, it's not suited to the development needs of independent innovation. The government of Guangdong shall change their mindsets and map plan out from the long-term strategic perspective, deploy the resources reasonably and increase financial funds in science and technology research to institutes and universities.

\section{References}

[1] Zhao xincheng: Analysis of factors reflected the growth of Guangdong province economy. Special Zone Economy, Vol. 281(6), (2012), p. 27

[2] China statistical yearbook on science and technology, 2002-2012

[3] Guangdong province statistical yearbook on science and technology, 2002-2011

[4] Chen jin: Roads of Guangdong chase Four Asia tigers. Publisher: Shantou University Press, (2008)

[5] Dou penghui, Chen shibo: Analysis of influence factors and performance evaluation of the scientific and technological innovation ability in China. Science \& Technology Progress and Policy, Vol. 29(7), (2012), p. 133

[6] Lv liangwen: Analysis and suggestion of expenditure based on Guangdong. GD Science \& Technology, Vol. 21(2), (2012), p. 1 